\title{
Outcome of Respiratory Distress in Neonates with Bubble CPAP at Neonatal Intensive Care Unit of a Tertiary Hospital
}

\author{
Sunil Raja Manandhar ${ }^{1}$ \\ 'Department of Pediatrics, Kathmandu Medical College Teaching Hospital, Sinamangal, Nepal.
}

\section{ABSTRACT}

Introduction: Respiratory distress is one of the commonest problem seen in neonates during admission in Neonatal Intensive Care Unit. Hyaline Membrane disease, Meconium Aspiration Syndrome, septicemia, congenital pneumonia, Transient Tachypnea of Newborn are the major causes of respiratory distress in neonates. Bubble Continuous Positive Airway Pressure is a non-invasive respiratory support delivered to a spontaneously breathing newborn to maintain lung volume during expiration. The main objective of this study was to observe the outcome of respiratory distress in neonates with Bubble Continuous Positive Airway Pressure.

Methods: This was a descriptive cross-sectional study conducted at Kathmandu Medical College Teaching Hospital over six months (October 2018 - March 2019) period. All preterm, term and post term babies with respiratory distress were included. Ethical clearance was received from Institutional Review Committee of Kathmandu Medical College and statistical analysis was done with SPSS 19 version.

Results: Sixty three babies with respiratory distress were included in this study with 45 (71\%) male predominance. The mean birth weight receiving Bubble Continuous Positive Airway Pressure was $2661.75 \pm 84$ gms and gestational age was $36.67 \pm 3.4$ wks. The Bubble Continuous Positive Airway Pressure was started at $8.05 \pm 2 \mathrm{hr}$ of life and duration of Bubble Continuous Positive Airway Pressure required for settling respiratory distress was $95.71 \pm 3 \mathrm{hrs}$. Out of 63 babies, improvement of respiratory distress in neonates with Bubble Continuous Positive Airway Pressure was 39 (61\%) with confidence interval of $38 \%$ to $62 \%$ whereas $24(39 \%)$ babies required mechanical ventilation and other modalities.

Conclusions: This study concludes usefulness of Bubble Continuous Positive Airway Pressure in neonates with respiratory distress.

Keywords: bubble CPAP; neonates; respiratory distress.

\section{INTRODUCTION}

Respiratory distress is one of the most common problem occurring; $5 \%$ in term and $29 \%$ in preterm babies requiring admission in Neonatal Intensive Care Unit (NICU) leading to $20 \%$ of neonatal deaths. ${ }^{1-3}$ Saeed $Z$ et al. described respiratory distress as the most common presenting problem encountered within the first 48-72 hours of life with a prevalence of $4.24 \%$ in neonates. ${ }^{4}$
Hyaline Membrane Disease (HMD), Meconium Aspiration Syndrome (MAS), septicemia, congenital pneumonia, Transient Tachypnea of Newborn (TTN) are the major causes of respiratory distress in preterm, term and post

Correspondence: Dr. Sunil Raja Manandhar, Department of Pediatrics, Kathmandu Medical College Teaching Hospital, Sinamangal, Nepal. Email: drsunilraja@gmail.com, Phone: +977-9803812218. 
term neonates. ${ }^{5}$

Continuous Positive Airway Pressure (CPAP) is an effective therapy for managing respiratory distress in preterm, term and post term neonates. ${ }^{6}$ CPAP is the application of positive pressure $(4-6 \mathrm{~cm}$ of water) to the airways of spontaneously breathing babies throughout the respiratory cycle to reduce work of breathing, preventing lung collapse by maintaining functional residual capacity. ${ }^{7-10}$

The main objective of this study was to observe the outcome of respiratory distress in neonates with Bubble CPAP (B-CPAP).

\section{METHODS}

This was a descriptive cross-sectional study done at 10 bedded NICU of Pediatrics Department, Kathmandu Medical College Teaching Hospital (KMCTH), Sinamangal, Kathmandu. Perinatal Mortality Rate (PMR) of this tertiary hospital is $10 / 1000$ births and Neonatal mortality rate (NMR) is $4.5 / 1000$ live births. ${ }^{11}$ Ethical clearance was received from Institutional Review Committee (IRC) of Kathmandu Medical College and written consent was taken from parents after explaining the baby's condition requiring B-CPAP therapy. $\mathrm{B}-\mathrm{CPAP}$ is a non-invasive ventilation to deliver CPAP in a spontaneously breathing newborn to maintain lung volumes during expiration. ${ }^{12}$ The study period was of six months (October 2018 to March 2019) duration. All preterm, term and post term babies born at KMCTH with respiratory distress due to any cause eg. Hyaline membrane disease (HMD), Meconium Aspiration Syndrome (MAS), septicemia, congenital pneumonia, Transient Tachypnea of Newborn (TTN) and perinatal asphyxia were included in this study. Syndromic babies and lethal congenital anomalies (eg. meningomyelocel, anencephaly, gastroschisis and diaphragmatic hernia) were excluded.

Sample size estimation:

$$
\mathrm{s}=\mathrm{Z}^{2} \times \frac{\mathrm{p} \times \mathrm{q}}{\mathrm{d}^{2}}=384
$$

for definite population,

$$
\mathrm{n}=\mathrm{s} / 1+(\mathrm{s}-1) / \mathrm{N}=59.35
$$

where, $\quad s=$ calculated sample size for infinite population

$\mathrm{n}=$ sample size

$Z=1.96$ for Confidence Interval of $95 \%$

$p=$ prevalence of improvement of

respiratory distress in neonates with $\mathrm{B}-\mathrm{CPAP}, 50 \%$

$\mathrm{q}=1-\mathrm{p}$

$\mathrm{N}=$ definite population (70)

$\mathrm{d}=$ margin of error considering $6 \%$ as a non-response rate, Total sample size was 63.

Sixty three neonates were included in this study and convenient sampling method was applied.

Respiratory distress was documented by fast breathing (Respiratory rate $>60 / \mathrm{min}$ ) and followed by any one of the followings. ${ }^{13}$

1. Low $\mathrm{O}_{2}$ saturation $\left(\mathrm{SPO}_{2}<87 \%\right)$

2. Chest retraction

3. Grunting

4. Nasal flaring

5. Severe chest indrawing.

Severity of respiratory distress in neonates is assessed by Silverman's Anderson Respiratory Scoring. Silverman's score 0 indicates no respiratory distress, 4-6 indicates moderate respiratory distress and 7-10 indicates severe respiratory distress. Silverman score $\geq 4$ were eligible for keeping babies under B-CPAP. ${ }^{14}$

Details of birth history, type of delivery along with maternal variables eg. multiple births, Pregnancy Induced Hypertension, Prolonged Rupture of Membrane (PROM) were recorded. Babies variables eg. birth weight, gestational age, Apgar score at 1 minute and 5 minute, delivery room management (oxygen, tactile stimulation, bag and mask ventilation and intubation), silverman's scoring before and after starting B-CPAP were also recorded. Following parameters were observed during the study period: time of starting B-CPAP, respiratory rate before, during and after $\mathrm{B}-\mathrm{CPAP}$, total duration required to wean off B-CPAP, any case of B-CPAP failure requiring mechanical ventilation. The other clinical data recorded are Patent Ductus Arteriosus (PDA), Atrial Septal Defect (ASD) and Ventricular Septal Defect (VSD) (clinical and Echo proven), pneumothorax, culture positive sepsis, duration of hospital stay among the survivors. In this study, more term and normal birth weight babies could be studied, which could improve the outcome of B-CPAP. Statistical analysis was done with SPSS 19 version.

\section{RESULTS}

There were total of 63 babies with respiratory distress included in this study. The mean birth weight of babies receiving $\mathrm{B}-\mathrm{CPAP}$ was $2661.75 \pm 84 \mathrm{gms}$ and mean gestational age was $36.67 \pm 3.4$ weeks. Similarly, mean Silverman's score before starting B-CPAP was $5.03 \pm 1.13$ and mean age of starting B-CPAP due to grunting and chest retraction was $8.05 \pm 26.03 \mathrm{hr}$ of life. Total mean duration of B-CPAP required to settle 
respiratory distress in neonates with respiratory distress was $95.71 \pm 36.7 \mathrm{hrs}$. Mean duration of babies kept under mechanical ventilation was $15.06 \pm 42.1 \mathrm{hrs}$ and mean hospital stay among the survivor neonates was $8 \pm 3.37$ days (Table 1 ).

Table 1. Demographics and clinical parameters of babies under B-CPAP $(n=63)$.

\begin{tabular}{|c|c|c|c|}
\hline S.N. & Variables & Mean & Range \\
\hline 1 & Gestational Age & $36.67 \pm 3.4$ & $\begin{array}{l}(28-41) \\
\text { wks. }\end{array}$ \\
\hline 2 & Birth weight & $\begin{array}{l}2661.75 \pm \\
84\end{array}$ & $\begin{array}{l}\text { (800 -4500) } \\
\text { gms }\end{array}$ \\
\hline 3 & $\begin{array}{l}\text { Silverman's score } \\
\text { before starting } \\
\text { Bubble CPAP }\end{array}$ & $5.03 \pm 1.13$ & $(4-8)$ \\
\hline 4 & $\begin{array}{l}\text { Mean age of } \\
\text { Bubble } \\
\text { started }\end{array}$ & $8.05 \pm 26.03$ & $(1-192) \mathrm{hrs}$ \\
\hline 5 & $\begin{array}{l}\text { Apgar Score at } 1 \\
\text { min }\end{array}$ & $6.54 \pm 1.70$ & $(3-8)$ \\
\hline 6. & $\begin{array}{l}\text { Apgar Score at } 5 \\
\text { min }\end{array}$ & $7.89 \pm 1.30$ & $(4-9)$ \\
\hline 7 & Mothers Age & $27.19 \pm 3.6$ & $\begin{array}{l}(19-38) \\
\text { yrs. }\end{array}$ \\
\hline 8 & $\begin{array}{l}\text { Mean duration of } \\
\text { Maternal PROM } \\
\text { (15 mothers) }\end{array}$ & $37 \pm 24.2$ & (18-96) hrs \\
\hline 9 & $\mathrm{SPO} 2$ in room air & $84.73 \pm 2.16$ & $(80-88) \%$ \\
\hline 10 & $\begin{array}{l}\text { Total duration } \\
\text { of Bubble CPAP } \\
\text { required }\end{array}$ & $95.71 \pm 36.7$ & $\begin{array}{l}(24-192) \\
\text { hrs }\end{array}$ \\
\hline 11 & $\begin{array}{l}\text { Total duration } \\
\text { of Mechanical } \\
\mathrm{V} \text { e } \mathrm{n} \mathrm{t} \mathrm{i} \text { a } \mathrm{t} \mathrm{i} \text { o } \mathrm{n} \\
\text { required due to } \\
\mathrm{B}-\mathrm{CPAP} \text { failure } \\
\text { (12 babies) }\end{array}$ & $15.06 \pm 42.1$ & (0- 240)hrs \\
\hline 12 & 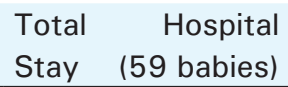 & $8 \pm 3.37$ & (3- 15 )days \\
\hline
\end{tabular}

Forty five $(71 \%)$ babies were term with male predominance $47(75 \%)$. Out of 63 babies, 38 (60\%) babies were of normal birth weight, regarding neonatal resuscitation, $42(67 \%)$ babies did not require any form of resuscitation and only $4(8 \%)$ babies required extensive neonatal resuscitation. The most common disease for starting B-CPAP was congenital pneumonia $15(23 \%)$ followed by MAS $12(19 \%)$ and Birth Asphyxia $8(13 \%)$. There were $7(11 \%)$ babies each had HMD and neonatal sepsis. Six babies (10\%) were diagnosed as congenital acyanotic heart disease by Echo, out of which four had isolated ASD, one had ASD with VSD and one had ASD with PDA. During the study period, a total of 24 (39\%) babies required additional treatment apart from B-CPAP. Twelve (19\%) babies required mechanical ventilation due to B-CPAP failure and $4(8 \%)$ babies with HMD required Surfactant Replacement Therapy (SRT) . Similarly 6 (10\%) babies received Frusemide for Echo proven severe pulmonary artery hypertension (PAH), $1(2 \%)$ baby was treated with water seal drainage for right sided Pneumothorax and $1(2 \%)$ baby required sodium bicarbonate correction for severe metabolic acidosis with neonatal sepsis. Out of 63 babies, $59(94 \%)$ babies were survived and only $4(6 \%)$ babies were expired. Prevalance of improved respiratory distress with B-CPAP was $39(61 \%)$ at $95 \%$ confidence interval [38\%-62\%]. Three babies died due to septicemia with DIC and one baby died due to pulmonary hemorrhage. The commonest complication of B-CPAP seen in 10 (16\%) neonates was superficial skin abrasion under the nose and over the cheeks. Four $(6 \%)$ babies each had gastric distension and acquired secondary infection whereas $1(2 \%)$ each had right sided pneumothorax and recurrent apnea respectively (Table 2).

\begin{tabular}{|c|c|c|c|}
\hline S.N. & Variables & $\mathbf{n}$ & (\%) \\
\hline \multirow[t]{4}{*}{1.} & Baby sex & & \\
\hline & Male & 47 & (75) \\
\hline & Female & 16 & (25) \\
\hline & Total & 63 & $(100)$ \\
\hline \multirow[t]{4}{*}{2.} & Gestation & & \\
\hline & Preterm & 18 & (29) \\
\hline & Term & 45 & (71) \\
\hline & Total & 63 & (100) \\
\hline \multirow[t]{6}{*}{3.} & Birth weight & & \\
\hline & $\begin{array}{l}\text { Extremely low birth weight } \\
(<1 \mathrm{~kg})\end{array}$ & 2 & (3) \\
\hline & Very low birth weight $(<1.5 \mathrm{~kg})$ & 8 & (13) \\
\hline & Low birth weight $(<2.5 \mathrm{~kg})$ & 15 & (24) \\
\hline & Normal birth weight $(2.5-4 \mathrm{~kg})$ & 38 & (60) \\
\hline & Total & 63 & (100) \\
\hline \multirow[t]{6}{*}{4.} & $\begin{array}{l}\text { Resuscitation procedure done at } \\
\text { birth }\end{array}$ & & \\
\hline & Not required & 42 & (67) \\
\hline & Tactile stimulation & 5 & (7) \\
\hline & Bag n Mask & 12 & (19) \\
\hline & $\begin{array}{l}\text { Bag } n \text { Mask and Chest } \\
\text { Compression }\end{array}$ & 1 & (2) \\
\hline & $\begin{array}{l}\text { Bag n Mask, Chest Compression } \\
\text { and Intubation }\end{array}$ & 2 & (3) \\
\hline
\end{tabular}


Bag n Mask, Chest Compression , Intubation and drug

Total

$63(100)$

5. Mode of delivery

Emergency cesarean section

41

Elective cesarean section

Normal delivery

13

Total

63

(100)

6 Causes of Respiratory Distress requiring Bubble CPAP

6.1 Congenital Pneumonia

o Maternal history of PROM 9

o Maternal High Vaginal Swab (HVS) culture positive

o Other

Total

15

6.2 Meconium Aspiration Syndrome 12

6.3 Birth Asphyxia

$\begin{array}{cccc}\text { O } & \text { HIE stage I } & 2 & \text { (3) } \\ \text { o } & \text { HIE stage II } & 6 & \text { (10) } \\ & \text { Total } & 8 & \text { (13) }\end{array}$

6.4 Hyaline Membrane Disease (HMD)

O Grade II 2

o Grade III

o Grade IV 3

Total

6.5 Congenital Acyanotic Heart Disease

o Atrial Septal Defect (ASD)

Atrial Septal Defect 4

o ASD with Ventricular 1

Septal Defect (VSD)

o ASD with PDA (Patent Ductus Arterious)

Total

6.6 Neonatal Sepsis

$\begin{array}{llll}\text { o } & \text { Culture positive sepsis } & 4 & 16) \\ \text { O } & \text { Culture negative sepsis } & 3 & 15 \\ \text { Total } & & 7 & (11)\end{array}$

\begin{tabular}{|c|c|c|c|}
\hline 6.7 & $\begin{array}{l}\text { Transient Tachypnea of Newborn } \\
\text { (TTN) }\end{array}$ & 6 & (10) \\
\hline \multirow[t]{2}{*}{6.8} & Aspiration Pneumonia & 2 & (3) \\
\hline & Total & 63 & (100) \\
\hline \multirow[t]{8}{*}{7} & Additional treatment required & & \\
\hline & $\begin{array}{l}\text { Respiratory support by B-CPAP } \\
\text { only }\end{array}$ & 39 & (61) \\
\hline & $\begin{array}{l}\text { Mechanical ventilation for } \\
\text { B-CPAP failure }\end{array}$ & 12 & (19) \\
\hline & $\begin{array}{l}\text { Frusemide for severe Pulmonary } \\
\text { artery hypertension(PAH) }\end{array}$ & 6 & (10) \\
\hline & $\begin{array}{l}\text { Surfactant Replacement Therapy } \\
\text { (SRT) for HMD }\end{array}$ & 4 & (6) \\
\hline & $\begin{array}{l}\text { Water seal drainage for } \\
\text { Pneumothorax }\end{array}$ & 1 & (2) \\
\hline & $\begin{array}{l}\text { Sodium bicarbonate correction } \\
\text { for severe metabolic acidosis } \\
\text { with neonatal sepsis }\end{array}$ & 1 & (2) \\
\hline & Total & 63 & $(100)$ \\
\hline \multirow[t]{4}{*}{8} & $\begin{array}{l}\text { Outcome of babies under Bubble } \\
\text { CPAP }\end{array}$ & & \\
\hline & Survived & 59 & (94) \\
\hline & Expired & 4 & (6) \\
\hline & Total & 63 & $(100)$ \\
\hline \multirow[t]{4}{*}{9} & Cause of death & & \\
\hline & Pulmonary hemorrhage & 1 & (2) \\
\hline & Septicemia with DIC & 3 & (5) \\
\hline & Total & 4 & (6) \\
\hline \multirow[t]{8}{*}{10} & Complication of Bubble CPAP & & \\
\hline & No complication & 43 & (68) \\
\hline & Superficial skin abrasion & 10 & (16) \\
\hline & Secondary infection & 4 & (6) \\
\hline & Gastric distension & 4 & (6) \\
\hline & Right sided Pneumothorax & 1 & (2) \\
\hline & Recurrent Apnea & 1 & (2) \\
\hline & Total & 63 & $(100)$ \\
\hline
\end{tabular}

The study highlighted that mean duration of B-CPAP use within $24 \mathrm{hrs}$ was $94.47 \pm 36.9 \mathrm{hrs}$ and after 24 hrs was $128 \pm 13.8$ hrs (Table 3 ).

Before B-CPAP, the mean respiratory rate was $83.02 \pm 7 /$ min, which had decreased after 48-96 hrs of B-CPAP. Similarly, the initial PEEP required before B-CPAP was $5.63 \pm 0.6 \mathrm{~cm}$ of water, which was decreased after 
48-96 hrs of B-CPAP. It showed decreasing trend of respiratory rate and PEEP pressure requirement after the use of B-CPAP (Table 3).

Table 3. Time of starting B-CPAP with respect to its duration and time to wean.

\begin{tabular}{|lccccccc|}
\hline & \multicolumn{2}{c}{ Age of starting B-CPAP } & Duration of B-CPAP required & \multicolumn{2}{c|}{$\begin{array}{l}\text { Time required to wean } \\
\text { off from B-CPAP }\end{array}$} \\
& Mean & Range & Mean & Range & Mean & Range \\
$\begin{array}{l}\text { B-CPAP started within 24 hrs } \\
(\mathrm{n}=59)\end{array}$ & $2.83 \pm 2.6$ & $(1-12) \mathrm{hrs}$ & $94.47 \pm 36.9$ & $(24-192) \mathrm{hrs}$ & $4.28 \pm 2.02$ & $(2-12)$ days \\
$\begin{array}{l}\text { B-CPAP started after } 24 \mathrm{hrs} \\
(\mathrm{n}=4)\end{array}$ & $85 \pm 73.7$ & $(26-192) \mathrm{hrs}$ & $128 \pm 13.8$ & $(120-144) \mathrm{hrs}$ & $6.75 \pm 2.8$ & $(3-10)$ days \\
\hline
\end{tabular}

Table 4. Clinical parameters under B-CPAP.

\begin{tabular}{|c|c|c|c|c|}
\hline & \multicolumn{2}{|c|}{ Respiratory Rate } & \multicolumn{2}{|c|}{ PEEP requirement } \\
\hline & Mean & Range & Mean & Range \\
\hline Before B-CPAP & $\begin{array}{l}83.02 \pm 7.4 \\
(n=63)\end{array}$ & $(68-110) / \min$ & $\begin{array}{l}5.63 \pm 0.6 \\
(n=63)\end{array}$ & (4-7) $\mathrm{cm}$ of water \\
\hline At $48 \mathrm{hrs}$ of B-CPAP & $\begin{array}{l}73.23 \pm 9.3 \\
(n=61)\end{array}$ & $(50-90) / \min$ & $\begin{array}{l}4.98 \pm 0.7 \\
(n=61)\end{array}$ & (4-7) $\mathrm{cm}$ of water \\
\hline At 72 hrs of B-CPAP & $\begin{array}{l}63.75 \pm 9.8 \\
(n=53)\end{array}$ & $(46-86) / \min$ & $\begin{array}{l}4.87 \pm 0.7 \\
(n=53)\end{array}$ & (4-7) $\mathrm{cm}$ of water \\
\hline At $96 \mathrm{hrs}$ of B-CPAP & $\begin{array}{l}59.91 \pm 9.9 \\
(n=35)\end{array}$ & $(42-80) / \min$ & $\begin{array}{l}4.51 \pm 0.7 \\
(n=35)\end{array}$ & (4-7) $\mathrm{cm}$ of water \\
\hline
\end{tabular}

\section{DISCUSSION}

This descriptive cross-sectional study included all newborns (preterm and term) with respiratory distress who were treated with B-CPAP as the primary respiratory support. The included newborns were mostly term $(71 \%)$ and $60 \%$ babies were of normal weight $(2.5-4$ $\mathrm{kg})$. The controversy of early vs delayed CPAP continues to have many trials favoring early CPAP were carried out to be better in the larger infants prior to routine use of antenatal steroids and postnatal surfactant. ${ }^{15}$ The evidence suggested exogenous surfactant use with early CPAP with brief ventilation in extremely Low Birth Weight (ELBW) babies had decreased the use of mechanical ventilation. ${ }^{16}$ Similarly, this study also showed B-CPAP within 24 hrs (early CPAP) in neonates with respiratory distress was effective in reducing respiratory effort and required lesser duration $(94.47 \pm 36.9 \mathrm{hrs})$ of B-CPAP as compared to after 24 hrs $(128 \pm 13.8 \mathrm{hrs})$. This finding was also strongly supported by the study done by Mathai SS et al, in which B-CPAP use within 24 hrs had less duration of $\mathrm{B}$-CPAP $(44.93 \pm 24.56 \mathrm{hrs})$ required as compared to after $24 \mathrm{hrs}(85.57 \pm 54.16 \mathrm{hrs}) .{ }^{17}$
This study described the commonest cause of respiratory distress requiring B-CPAP was congenital pneumonia (23\%) followed by MAS (19\%), birth asphyxia (13\%) and HMD (11\%). Mathur NB et al. postulated congenital pneumonia as the main cause of respiratory distress $(68 \%)$ with maternal history of PROM $\geq 24$ hrs as one of the risk factor for it. ${ }^{18}$ This study also corroborated similar findings as out of 15 babies with congenital pneumonia, nine babies had maternal history of PROM highlighting it as one of the major risk factor.

Lanieta et al successfully demonstrated the usefulness of B-CPAP in developing countries highlighting its cost effectiveness. ${ }^{19}$ Similarly in this study, out of 63 babies with B-CPAP 39 (61\%) babies were improved.

Since, this is a single institutional study with convenient sampling, outcome might not be generalized. There are chances of selection bias.

\section{CONCLUSIONS}

This study concludes usefulness of Bubble Continuous Positive Airway Pressure in neonates with respiratory distress. 
Manandhar. Outcome of Respiratory distress in Neonates with Bubble CPAP at Neonatal Intensive Care Unit of a Tertiary Hospital

\section{ACKNOWLEDGEMENTS}

My sincere hearty thanks and acknowledgment to all the Pediatric faculties and post graduate residents for their tireless effort during duty hours and contribution in NICU to make this study successful.

Conflict of Interest: None.

\section{REFERENCES}

1. Edwards MO, Kotecha SJ, Kotecha S. Respiratory distress of the term newborn infant. Paediatr Respir Rev. 2013;14(1):29-36. [PubMed | Full Text | DOI]

2. Neonatal morbidity and mortality: Report of the National Neonatal Perinatal database. Indian Pediatr. 1997;34(11):1039-42. [PubMed]

3. Hibbard JU, Wilkins I, Sun L, Gregory K, et al. Respiratory morbidity in late preterm births. JAMA. 2010;304(4):419-25. [ PubMed | Full Text | DOI]

4. Saeed Z, Lutufullah G, Hassan R. Prevalence and aetiology of respiratory distress in newborns. Pak Armed Forces Med J. 2013 Mar;63(1):22-5. [Full Text]

5. Reuter S, Moser C, Baack M. Respiratory distress in the newborn. Pediatr Rev. 2014 Oct;35(10):417-29. [PubMed | Full Text | DOI]

6. Buckmaster A. Nasal continuous positive airway pressure for respiratory distress in non-tertiary care centres: what is needed and where to from here? J Paediatr Child Health. 2012;48(9):747-52. [Full Text]

7. American Association of Respiratory Care. Application of continuous positive airway pressure to neonates via nasal prongs, nasopharyngeal tube or nasal mask - 2004 revision \& update. Respir care. 2004;49(9):1100-8. [Full Text]

8. Davis PG, Henderson-Smart DJ. Nasal continuous positive airways pressure immediately after extubation for preventing morbidity in preterm infants. Cochrane Database Syst Rev. 2003;(2):CD000143. [Full Text]

9. De Paoli AG, Davis P, Faber B, Morley CJ. Devices and pressure sources for administration of nasal continuous positive airway pressure (NCPAP) in preterm neonates. Cochrane Database of Systematic Reviews. 2008(1);CD002977. [PubMed | Full Text | DOI]

10. Ho JJ, Henderson-Smart DJ, Davis P. Early versus delayed initiation of continuous distending pressure for respiratory distress syndrome in preterm infants. Cochrane Database of Systematic Reviews 2002;(2):CD002975. [Full Text | DOI]
11. Manandhar SR. Outcome of surfactant replacement therapy in preterm babies with hyaline membrane disease at neonatal intensive care unit of a tertiary hospital. BJHS. 2018;3(3):486-8. [․ㅏll Text | DOI]

12. Morley CJ, Lau R, De Paoli A, Davis PG. Nasal continuous positive airway pressure: does bubbling improve gas exchange? Archives of Disease in Childhood: Fetal and Neonatal Edition. 90(4):F343-4. [Full Text | DOI]

13. Saha LC, Chowdhury MA, Hoque MdM ,Al Mamun MdA, Rahman M. Effect of bubble CPAP in PT lbw neonates with respiratory distress. Acad J Ped Neonatol. 2017;3(2):1-6. [Full Text]

14. Askin DF. Complications in the transition from fetal to neonatal life. J Obstet Gynecol Neonatal Nurs. 2002;31(3):318-27. [PubMed]

15. Ho JJ, Henderson-Smart DJ, Davis PG. Early versus delayed initiation of continuous distending pressure for respiratory distress syndrome in preterm infants. Cochrane Database Syst Rev. 2002;(2):CD002975. [Full Text]

16. Verder $H$, Albertsen $P$, Ebbesen F. Greisen G, Robertson B, Bertelsen A, et al. Nasal continuous positive airway pressure and early surfactant therapy for respiratory distress syndrome in newborns of less than 30 weeks gestation. Pediatrics. 1999;103(2):E24 [PubMed | Full Text]

17. Mathai SS, Rajeev A, Adhikari KM. Safety and effectiveness of bubble continuous positive airway pressure in preterm neonates with respiratory distress. Medical J Armed Forces India. 2014 Oct;70(4):327-31. [PubMed | Full Text | DOI]

18. Mathur NB, Garg K, Kumar S. Respiratory distress in neonates with special reference to pneumonia. Indian Pediatr. 2002;39(6):529-37. [PubMed]

19. Koyamaibole L, Kado J, Qovu J, Colquhoun S, Duke T. An evaluation of bubble-CPAP in a neonatal unit in a developing country: effective respiratory support that can be applied by nurses. J Trop Pediatr. 2006;52(4):249-53. [PubMed | Full Text | DOI]

This work is licensed under a Creative Commons Attribution 4.0 International License. The images or other third party material in this article are included in the article's Creative Commons license, unless indicated otherwise in the credit line; if the material is not included under the Creative Commons license, users will need to obtain permission from the license holder to reproduce the material. To view a copy of this license, visit http: creativecommons.org/licenses/by/4.0 